11 Landefeld CS, Goldman L. Major bleeding in outpatients treated with warfarin: incidence and prediction by factors known at the start of outpatient therapy. Am F Med 1989;87:144-52.

12 Lundström T Ryde'n L Haemorrhagic and thrombotic complications in patients with atrial fibrilation on anticoagulant prophylaxis. $\mathcal{I}$ Int $M$ patients with atrial

13 Carlsson A, Gustafsson C. Blödningskomplikationer till antikoagulantiabehandling. Abstract vid workshop om förmaksflimmer. Läkemedelsverke 1992;1:21-4

14 Wintzen AR, de Jonge $H$, Loegliger EA, Bots GTAM. The risk of intracerebral hemorrhage during oral anticoagulant treatment: a population study. Ann Neurol 1984;16:553-8.

15 UK-TIA Study Group. The United Kingdom transient ischaemic attack (UK-TIA) aspirin trial: final results. $f$ Neurol Neurosurg Psychiatry 1991;54 1044-54.

16 Terent $\mathrm{A}$. Kostnader för stroke vård. Läkartidningen (in press)

17 Persson U, Silverberg R, Lindgren B, Norrving B, Jadbäck G, Johansson B et al. Direct costs of stroke for a Swedish population. Int $\mathcal{f}$ Technol Assess Health Care 1990;6:125-37.

18 Stroke. Towards better management. London: Royal College of Physicians, 1989
19 Isard PA, Forbes JF. The cost of stroke to the National Health Service in Scotland. Cerebrovasc Dis 1992;2:47-50.

Swedish Bureau of Statistics. Arbetskraftsunderö̈kningen, Arsmedeltal 1990 Stockholm: Swedish Bureau of Statistics, 1990.

Swedish Bureau of Statistics. Inkomstfördelningsundersökningen 1989. Stockholm: Swedish Bureau of Statistics, 1989. (BE 21 SM 9101 )

22 Swedish Bureau of Statistics. Fordjonst 31 December 1990. Stockholm: Swedish Bureau of Statistics, 1990. (S 20 SM 9101)

23 Lancaster TR, Singer DE, Sheehan MA, Oertel LB, Maraventano SW, Hughes RA, et al. The impact of long-term warfarin therapy on quality of life. Arch Interm Med 1991;151:1944-9.

24 The Stroke Prevention in Atrial Fibrillation Investigators. Predictors of thromboembolism in atrial fibrillation. I. Clinical features of patients at risk. Ann Intern Med 1992;116:1-5.

25 The Stroke Prevention in Atrial Fibrillation Investigators. Predictors of thromboembolism in atrial fibrillation. II. Echocardiographic features of patients at risk. Ann Intern Med 1992;116:6-12.

\title{
Atrial fibrillation and stroke: prevalence in different types of stroke and influence on early and long term prognosis (Oxfordshire community stroke project)
}

Peter Sandercock, John Bamford, Martin Dennis, John Burn, Jim Slattery, Lesley Jones, Surat Boonyakarnkul, Charles Warlow

Department of Clinical Neurosciences, Western General Hospital, Edinburgh EH4 2XU Peter Sandercock, senior lecturer in neurology Martin Dennis, senior lecturer in stroke medicine

Jim Slattery, statistician Charles Warlow, professor of medical neurology

Department of Neurology, St James's University Hospital, Leeds LS9 7TF John Bamford, consultant neurologist

University Department of Rehabilitation Medicine, Southampton General Hospital, Southampton John Burn, senior registrar in rehabilitation medicine

Department of Community Medicine and General Practice, Gibson

Laboratories, Radcliffe

Infirmary, Oxford

OX2 6HE

Lesley Jones, programmer

Division of Neurology, Department of Medicine, Rajavithi Hospital Bangkok 10400, Thailand Surat Boonyakarnkul, neurologist

Correspondence to:

Dr Sandercock.

\section{Abstract}

Objective-To determine in patients with first ever stroke whether atrial fibrillation influences clinical features, the need to perform computed tomography, and prognosis.

Design-Observational cohort study with maximum follow up of 6.5 years.

Setting-Primary care, based on 10 general practices in urban and rural Oxfordshire.

Subjects-Consecutive series of 675 patients with first ever stroke registered in the Oxfordshire community stroke project.

Main outcome measures-Prevalence of atrial fibrillation by type of stroke; effect of atrial fibrillation on case fatality rate and risk of recurrent stroke, vascular death, and death from all causes.

Results-Prevalence of atrial fibrillation was $17 \%$ (95\% confidence interval $14 \%$ to $20 \%$ ) for all stroke types $(115 / 675), 18 \%(15 \%$ to $21 \%)$ for cerebral infarction $(97 / 545), 11 \%(4 \%$ to $11 \%)$ for primary intercerebral haemorrhage (7/66), and $0 \%$ ( 0 to $11 \%$ ) for subarachnoid haemorrhage $(0 / 33)$. For patients with cerebral infarction the $\mathbf{3 0}$ day case fatality rate was significantly higher with atrial fibrillation $(23 \%)$ than with sinus rhythm $(8 \%)$; the risk of early recurrent stroke (within 30 days) was $1 \%$ with atrial fibrillation and $4 \%$ with sinus rhythm. In patients who survived at least 30 days the average annual risk of recurrent stroke was $8 \cdot 2 \%(5.9 \%$ to $10.9 \%)$ with sinus rhythm and $11 \%(6 \cdot 0 \%$ to $17 \cdot 3 \%)$ with atrial fibrillation.

Conclusions-After a first stroke atrial fibrillation was not associated with a definite excess risk of recurrent stroke, either within 30 days or within the first few years. Survivors with and without atrial fibrillation had a clinically important absolute risk of further serious vascular events.

\section{Introduction}

People with atrial fibrillation have an increased risk of stroke compared with people with sinus rhythm ${ }^{1-10}$; if the arrhythmia is not associated with valvar heart disease the increase in risk may be only slight ${ }^{401011}$ or even non-existent. ${ }^{8}$ Primary prevention of stroke has been studied in several randomised trials in patients with atrial fibrillation, the results suggesting that a 3-6\% annual risk of stroke can be reduced by at least $20-40 \%$ with anticoagulant or antiplatelet treatment. ${ }^{12-14}$ Once a stroke has occurred it is not clear whether the subsequent early and long term risks of death or recurrent stroke are significantly different in patients with and without atrial fibrillation. Some? studies have suggested that atrial fibrillation is associated with an increased risk of death in the first four weeks after a stroke ${ }^{1516}$ whereas another has not. ${ }^{2}$ Similarly, some studies have suggested substantially higher early and long term risk of recurrent stroke in patients with atrial fibrillation compared with sinus rhythm ${ }^{17-19}$ whereas others suggested little if any difference. $^{220}$ The aim of this study was to determine the contribution of atrial fibrillation to the causation of different types of stroke and to the early and long term risks of death and recurrent stroke after a first stroke, thereby identifying priorities in the early and long term management of patients with stroke and atrial fibrillation. A study of prognosis should satisfy certain methodological criteria. ${ }^{21}$ The Oxfordshire community stroke project satisfies most, if not all, of these criteria. ${ }^{22} 23$

\section{Patients and methods}

The methods used in the Oxfordshire community stroke project and the characteristics of the cohort of patients with stroke have been described elsewhere. ${ }^{22}{ }^{23} \mathrm{G}$ Briefly, it was a prospective community based register of all new cases of acute cerebrovascular disease, including cases of stroke and transient ischaemic 0 ? attack, occurring in a defined population of about 0 105000 residents of Oxfordshire. Meticulous case 0 ascertainment methods were used to detect cases $\mathbb{D}$ whether patients were admitted to hospital, managed $\mathbb{D}$ at home, or treated elsewhere while temporarily resident outside Oxfordshire. All patients were seen as soon after the event as possible by one of the neuro- 0 logists on the study (PS, JB, MD, JB, or CW) and basic investigations including electrocardiography, chest흠 radiography, and computed tomography were per- formed. If computed tomography could not be performed and the patient died every effort was made to obtain a necropsy to determine the pathological type 
of stroke. The classification and definitions of the different pathological types of stroke are detailed elsewhere. ${ }^{22} 23$

We included only patients with their first ever stroke. Detailed definitions of the subtypes of cerebral infarction are given elsewhere. ${ }^{24} 25$

Definition of atrial fibrillation - The diagnosis of atrial fibrillation must $(a)$ have been confirmed by an electrocardiogram showing either absent $\mathrm{p}$ waves or atrial flutter with an irregular ventricular response and (b) have been documented before the stroke, at the time of assessment by the project team, or within one month after the onset of the first stroke. Patients first found to have atrial fibrillation more than one month after the stroke who did not have atrial fibrillation at the time of the stroke or before were classified as having sinus rhythm. Ambulatory monitoring of electrocardiograms was not routinely performed.

Follow up-Two research nurses followed up the patients at one month, six months, one year, and annually thereafter. Patients who left the area were traced through their general practitioner. The final follow up examination of all survivors irrespective of their area of residence was performed by one of the study neurologists between August 1987 and October 1988.

Recurrent stroke and vascular death-All patients with suspected recurrent stroke were re-examined by one of the study neurologists as soon after the event as possible; the clinical data on all such events were then reviewed at regular consensus meetings of the study team. At the final follow up examination by the neurologist all medical records (including the general practitioners') that related to any suspected recurrent

TABLE I-Prevalence of atrial fibrillation in different types of stroke and subtypes of cerebral infarction. Prevalence in transient ischaemic attacks ${ }^{28}$ is shown for comparison

\begin{tabular}{|c|c|c|c|c|c|c|}
\hline & \multicolumn{3}{|c|}{$\begin{array}{l}\text { Patients with atrial fibrillation } \\
\text { at any time }\end{array}$} & \multicolumn{3}{|c|}{$\begin{array}{l}\text { Patients with atrial fibrillation } \\
\text { before stroke }\end{array}$} \\
\hline & No & $\%$ & $\begin{array}{c}95 \% \\
\text { Confidence } \\
\text { interval }\end{array}$ & No & $\%$ & $\begin{array}{c}95 \% \\
\text { Confidence } \\
\text { interval }\end{array}$ \\
\hline \multicolumn{7}{|l|}{ Type of stroke: } \\
\hline Cerebral infarction $(n=545)$ & 97 & 18 & 15 to 21 & 61 & 63 & 52 to 72 \\
\hline $\begin{array}{l}\text { Primary intracerebral haemorrhage } \\
(n=66)\end{array}$ & 7 & 11 & 4 to 11 & 5 & 71 & 29 to 96 \\
\hline Subarachnoid haemorrhage $(n=33)$ & 0 & 0 & 0 to 11 & 0 & 0 & \\
\hline Not known $(n=31)$ & 11 & 35 & 19 to 55 & 7 & 64 & 31 to 89 \\
\hline All $(n=675)$ & 115 & 17 & 14 to 20 & 73 & 63 & 55 to 72 \\
\hline Transient ischaemic attack $(n=184)$ & 26 & 14 & 9 to 19 & Not known & Not known & \\
\hline \multicolumn{7}{|l|}{ Subtype of cerebral infarction $(n=543) \dagger$ : } \\
\hline Lacunar $(n=137)$ & 18 & 13 & 7 to 19 & 9 & 50 & 27 to 73 \\
\hline Partial anterior circulation $(n=185)$ & 35 & 19 & 13 to 25 & 24 & 69 & 53 to 84 \\
\hline Posterior circulation $(n=129)$ & 15 & 12 & 6 to 17 & 10 & 67 & 38 to 88 \\
\hline Total anterior circulation $(n=92)$ & 28 & 30 & 20 to 40 & 17 & 61 & 41 to 78 \\
\hline
\end{tabular}

*Before stroke, at time of stroke, within 1 month after stroke.

†Not determined in two cases.

TABLE II-Clinical features in patients with stroke with and without atrial fibrillation. Odds ratios are adjusted for age and type of stroke

\begin{tabular}{|c|c|c|c|c|}
\hline & $\begin{array}{l}\text { No (\%) with } \\
\text { atrial fibrillation } \\
(\mathrm{n}=115)\end{array}$ & $\begin{array}{l}\text { No }(\%) \text { with } \\
\text { sinus rhythm } \\
(\mathrm{n}=560)\end{array}$ & $\begin{array}{l}\text { Adjusted odds ratio } \\
\text { (95\% confidence } \\
\text { interval) }\end{array}$ & $\mathrm{p}$ Value \\
\hline Hypertension ${ }^{\star}$ & $68(59)$ & $307(55)$ & $1.2(0.8$ to 1.8$)$ & NS \\
\hline Ischaemic heart disease $\dagger$ & $37(32)$ & $145(26)$ & $1.4(0.9$ to $2 \cdot 1)$ & NS \\
\hline Cervical bruit $\ddagger$ & $6(5)$ & $66(12)$ & $0.4(0.2$ to 1.0$)$ & NS \\
\hline Peripheral vascular diseasel| & $28(24)$ & $113(20)$ & $1.3(0.8$ to $2 \cdot 0)$ & NS \\
\hline Diabetes mellitus & $17(15)$ & $46(8)$ & $1.9(1.1$ to 3.5$)$ & 0.04 \\
\hline Any valvar heart disease $e^{\star \star}$ & $30(26)$ & $48(9)$ & $3 \cdot 4(2 \cdot 0$ to $5 \cdot 7)$ & 0.000002 \\
\hline Definite mitral stenosist† & $5(4)$ & $2(0 \cdot 4)$ & $12 \cdot 7(2 \cdot 4$ to $66 \cdot 2)$ & 0.002 \\
\hline None of the above & $29(25)$ & $168(30)$ & $0.8(0.5$ to 1.2$)$ & NS \\
\hline
\end{tabular}

$\star$ Two recordings with systolic blood pressure $>160 \mathrm{~mm} \mathrm{Hg}$ and diastolic pressure $>90 \mathrm{~mm} \mathrm{Hg}$ before stroke.

* Two recordings with systolic blood pressure $>160 \mathrm{~mm} \mathrm{Hg}$ and diastolic pressure $>90 \mathrm{~mm} \mathrm{Hg}$ before stroke.
+ Confirmed myocardial infarction or angina before stroke or pathological $\mathrm{Q}$ waves consistent with previous †Confirmed myocardial infarction or angina before strok

myocardial infarction on electrocardiogram at time of stroke.
$\ddagger$ Non-transmitted arterial bruit audible over either internal carotid artery high in the neck or over either subclavian $\ddagger$ Non-transmitted arterial bruit
artery in supraclavicular fossa.

artery in supraclavicular fossa.

Requiring treatment with diet, insulin, or oral hypoglycaemic agents

$\star \star$ Any one of the following valvar heart lesions clinically diagnosed with or without confirmatory evidence from echocardiography: mitral stenosis, mitral incompetence, mitral leaflet prolapse, mitral annulus calcification, aortic stenosis, aortic sclerosis, or aortic incompetence.

††Diagnosed by characteristic clinical features, supported by chest radiography and electrocardiography and preferably confirmed by cardiologist with or without echocardiography.

NS $=p>0.05$. stroke were reviewed. Events were then classified as a definite recurrence if there was clear clinical evidence of the sudden onset of a new neurological deficit, or an increase in an existing deficit, for which no explanation other than a recurrent stroke could be found. Vascular death included deaths due to either the initial or recurrent stroke as well as sudden and unexplained death, sudden death presumed to have cardiac causes, death associated with cardiac disease, and death due to other vascular causes-for example, a ruptured aortic aneurysm. We planned analyses of survival in patients with cerebral infarction and in patients who survived at least 30 days after the first stroke.

Statistical methods-Confidence intervals for proportions, odds ratios, and differences of proportions were estimated using standard methods ${ }^{26} 27$; odds ratios were adjusted using log linear modelling. $p$ Values for two by two contingency tables were calculated from the $\chi^{2}$ statistic, or from Fisher's exact test ${ }^{27}$ when one or more expected cell frequencies were less than 5 . For tables with more cells the Mantel-Haenszel procedure was used to calculate a summary statistic and derive the odds ratio.

\section{Results}

PREVALENCE OF ATRIAI. FIBRILLATION IN DIFFERENT TYPES OF STROKL

In all, 115 out of 675 patients $(17 \%)$ had atrial fibrillation documented by electrocardiography. The prevalence of atrial fibrillation in the different pathological types of stroke and in different subtypes of cerebral infarction and the number known to have atrial fibrillation before stroke is given in table I.

CLINICAL FEATURES IN PATIENTS WITH AND WITHOUT ATRIAI. FIBRILI.ATION

The mean ages of patients with atrial fibrillation and sinus rhythm were $77(\mathrm{SD} 8.8)$ and $70.6(13.7)$ years respectively; the difference was significant $(\mathrm{p}<0.0001)$. The prevalence of vascular risk factors, of clinical evidence of large artery disease, and of valvar heart disease associated with atrial fibrillation is given in table II. Thyroid function was not systematically measured in all patients, but review of medical records in a subsample (a consecutive series of the first 323 cases of first stroke registered by the Oxfordshire community stroke project) showed that only one of the 46 patients with atrial fibrillation ( $2 \%$ (95\% confidence interval 0 to $6 \%$ )) had thyrotoxicosis.

USE OF ANTIPLATELET AND ANTICOAGUL ANT TREATMENT

Before stroke-Twenty nine of the 675 patients $(4.3 \%)$ and 11 of the $115(9 \cdot 6 \%)$ patients with atrial fibrillation were receiving antiplatelet treatment when the stroke occurred. Seven of the $675(1.0 \%)$ patients and four of the $115(3.5 \%)$ patients with atrial fibrillation were taking oral anticoagulants when the stroke occurred

After stroke-Antiplatelet and anticoagulant treatment were not used systematically after stroke. Of the 97 patients with atrial fibrillation and cerebral infarction, 21 received anticoagulant and 16 antiplatelet treatment at some time after the stroke; few of them were given long term maintenance treatment.

\section{CASE FATALITY RATES AT 30 DAYS}

In general, the case fatality rates at 30 days were significantly higher in patients with atrial fibrillation (table III); the twofold or threefold differences were not significant for all subgroups. The differences were significant for all stroke types combined and in patients with cerebral infarction. In patients with cerebral infarction the case fatality rates at 30 days were $23 \%(14.8 \%$ to $32 \cdot 3 \%)$ in those with atrial fibrillation 
TABLE III--Effect of atrial fibrillation on case fatality rate 30 days after stroke according to type of stroke, subtype of cerebral infarction, and age

\begin{tabular}{|c|c|c|c|c|c|c|}
\hline & \multirow[b]{2}{*}{$\begin{array}{l}\text { Atrial } \\
\text { fibrillation }\end{array}$} & \multicolumn{2}{|c|}{ No of patients: } & \multirow{2}{*}{$\begin{array}{l}30 \text { Day } \\
\text { case fatality } \\
\text { rate }(\%)\end{array}$} & \multirow{2}{*}{$\begin{array}{l}\text { Adjusted odds ratio } \\
\text { (95\% confidence } \\
\text { interval) }\end{array}$} & \multirow[b]{2}{*}{$\mathrm{p}$ Value } \\
\hline & & $\begin{array}{r}\text { Dead by } \\
30 \text { days }\end{array}$ & $\begin{array}{l}\text { Alive at } \\
30 \text { days }\end{array}$ & & & \\
\hline \multicolumn{7}{|l|}{ Type of stroke*: } \\
\hline \multirow{2}{*}{ Cerebral infarction } & + & 22 & 75 & 23 & & \\
\hline & - & 35 & 413 & 8 & $3.5(1.9$ to 6.2$)$ & 0.00003 \\
\hline Primary intracerebral haemorrhage & + & 4 & 3 & 57 & & \\
\hline \multirow{2}{*}{ Not known } & + & $\begin{array}{l}30 \\
10\end{array}$ & $\begin{aligned} 29 \\
1\end{aligned}$ & $\begin{array}{l}51 \\
91\end{array}$ & $1.3(0.3$ to 6.3$)$ & NS \\
\hline & - & 13 & 7 & 65 & $5.4(0.6$ to 51.2$)$ & NS \\
\hline \multirow{2}{*}{ All } & + & 36 & 79 & 31 & & \\
\hline & - & 78 & 449 & 15 & $3 \cdot 1(1.8$ to $5 \cdot 4)$ & 0.00001 \\
\hline \multicolumn{7}{|l|}{ Subtype of cerebral infarctiont: } \\
\hline \multirow{2}{*}{ Lacunar } & + & 2 & 16 & 11 & & \\
\hline & - & 1 & 118 & 1 & $14 \cdot 8(1.3$ to 172$)$ & 0.05 \\
\hline Partial anterior circulation & $\begin{array}{l}+ \\
-\end{array}$ & $\begin{array}{l}1 \\
7\end{array}$ & $\begin{array}{r}34 \\
143\end{array}$ & $\begin{array}{l}3 \\
5\end{array}$ & $0.6(0.1$ to $5 \cdot 1)$ & NS \\
\hline \multirow{2}{*}{ Posterior circulation } & + & 2 & 13 & 13 & (0) & \\
\hline & - & 7 & 107 & 6 & $2.4(0.4$ to 12.5$)$ & NS \\
\hline \multirow{2}{*}{ Total anterior circulation } & + & 16 & 12 & 57 & & \\
\hline & - & 20 & 44 & 31 & $2.9(1.2$ to 7.3$)$ & 0.05 \\
\hline \multirow{2}{*}{ All } & + & 21 & 75 & 22 & & \\
\hline & - & 35 & 412 & 8 & $2.5(1.3$ to 4.9$)$ & 0.007 \\
\hline \multicolumn{7}{|l|}{ Age (years) $\ddagger:$} \\
\hline $0-49$ & - & 4 & 38 & 10 & & \\
\hline \multirow{2}{*}{$50-59$} & + & 1 & 2 & 33 & & \\
\hline & - & 8 & 42 & 16 & $2 \cdot 6(0 \cdot 2$ to $32 \cdot 5)$ & NS \\
\hline \multirow[t]{2}{*}{$60-69$} & + & 4 & 15 & 21 & & \\
\hline & - & 19 & 103 & 16 & $1.4(0.4$ to 4.3$)$ & NS \\
\hline \multirow{2}{*}{$70-79$} & + & 14 & 35 & 29 & & \\
\hline & - & 26 & 172 & 13 & $2.6(1.3$ to 5.6$)$ & 0.02 \\
\hline \multirow[t]{2}{*}{$\geqslant 80$} & + & 17 & 27 & 39 & & \\
\hline & - & 36 & 112 & 24 & $2.0(1.0$ to 4.0$)$ & NS \\
\hline \multirow{2}{*}{ All ages, all types } & + & 36 & 79 & 31 & & \\
\hline & - & 93 & 467 & 17 & $2 \cdot 1(1 \cdot 3$ to $3 \cdot 4)$ & 0.001 \\
\hline
\end{tabular}

*All 33 patients with subarachnoid haemorrhage are excluded as none had atrial fibrillation (table I).

†Not determined in two cases, so $n=543$.

$\neq$ All 675 patients are included. rank statistic to test for the difference in survival between patients with atrial fibrillation and sinus rhythm, we found that atrial fibrillation was associated with a significant increase in the risk of death from all causes, of vascular death, and of recurrent stroke or vascular death, or both (table IV, fig 1). There was no significant excess of recurrent stroke in patients with atrial fibrillation (table IV, fig 2).

Unadjusted analyses in survivors of first cerebral infarction at 30 days - There was a significant excess of deaths from all causes in patients with atrial fibrillation, but no excess risk of vascular death, of recurrent stroke, or of recurrent stroke or vascular death (table IV, fig 3).

Average annual risks-The average annual risks of $\vec{\nabla}$ vascular events are given in table $\mathrm{V}$. The excess observed in patients with atrial fibrillation was not significant and, because of the small number of events, $\vec{\circ}$ the confidence intervals were wide. Our study had $\vec{\exists}$ sufficient power to exclude large differences in the long term risk of serious vascular events between patients

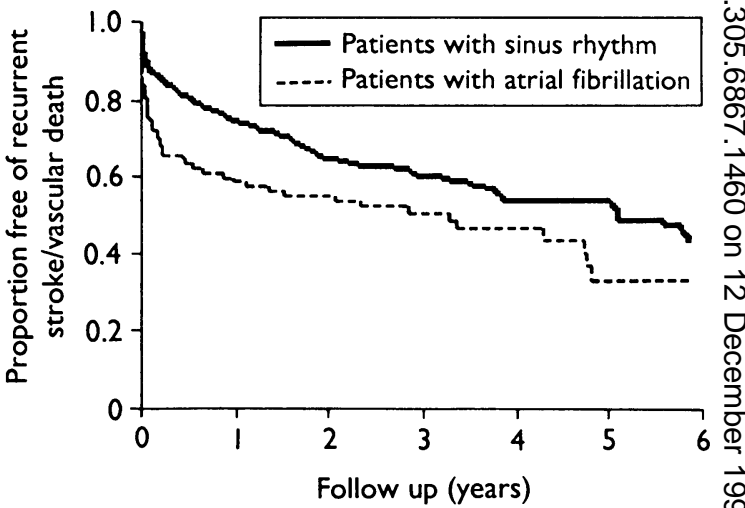

FIG 1-Survival free of recurrent stroke or vascular death, or both, in 545 patients with first ever cerebral infarction. Deaths from nonvascular causes are excluded. (Kaplan-Meier survival curve)

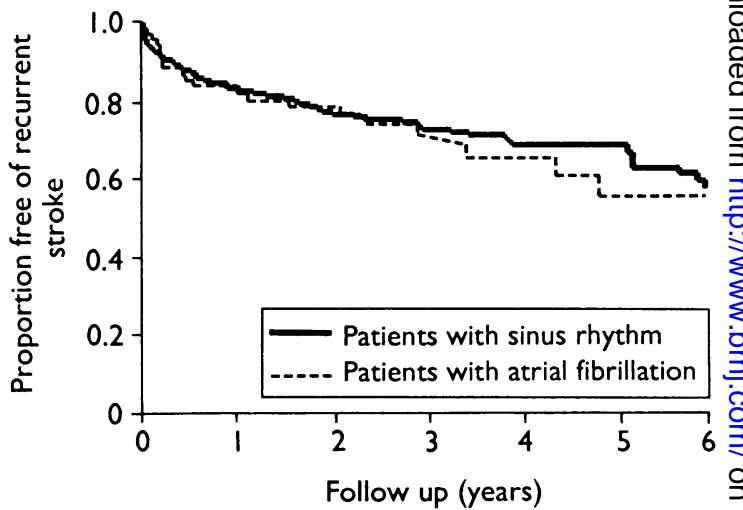

FIG 2-Survival free of recurrent stroke in 545 patients with first ever $\mathrm{N}$ cerebral infarction. Deaths from causes unrelated to stroke are excluded. (Kaplan-Meier survival curve)



FIG 3-Survival free of recurrent stroke or vascular death, or both, in 488 patients surviving at least 30 days after first cerebral infarction. Deaths from causes unrelated to stroke are excluded. (Kaplan-Meier survival curve) 
with atrial fibrillation and those with sinus rhythm, but we cannot exclude small differences in absolute risks; the confidence intervals include the possibilities that average annual risks might be $2-3 \%$ lower or, equally, that they are $9-12 \%$ higher in patients with atrial fibrillation compared with patients with sinus rhythm.

Proportional hazards analysis-Patients with atrial fibrillation had a higher mean age than those with sinus rhythm and were more likely to have large cerebral infarcts (table I). As age and subtype of cerebral infarction were highly significant predictors of long term outcome, we used Cox's proportional hazards model $^{30}$ to determine the independent effect of atrial fibrillation on survival beyond 30 days (table VI).

TABI.E V-Absolute risks: average annual risk over five year (calculated from life tables) in patients who survived at least 30 days after first ever cerebral infarction

\begin{tabular}{|c|c|c|}
\hline & $\underset{(\%)}{\text { Annual risk }}$ & $\begin{array}{l}95 \% \text { Confidence } \\
\text { interval }\end{array}$ \\
\hline \multicolumn{3}{|l|}{ Recurrent stroke: } \\
\hline Sinus rhythm & $8 \cdot 2$ & 5.9 to 10.9 \\
\hline Atrial fibrillation & $11 \cdot 0$ & 6.0 to 17.3 \\
\hline Difference $^{\star}$ & $2 \cdot 8$ & $-2 \cdot 6$ to 8.9 \\
\hline \multicolumn{3}{|c|}{ Recurrent stroke or vascular death: } \\
\hline Sinus rhythm & $11 \cdot 8$ & $9 \cdot 2$ to $14 \cdot 8$ \\
\hline Atrial fibrillation & $15 \cdot 8$ & $9 \cdot 9$ to $24 \cdot 1$ \\
\hline Difference $^{\star}$ & $4 \cdot 0$ & $-2 \cdot 3$ to 11.7 \\
\hline
\end{tabular}

*Not significant at $p<0.05$; adjustment for age and infarct type did not affect significance.

TARLE VI-Relative risks: analysis of effect of atrial fibrillation on long term prognosis, adjusting for age and subtype of infarction in 448 patients with first cerebral infarction who survived at least 30 days

\begin{tabular}{lccc}
\hline & & Relative risk/ & \\
Event & Relative risk & SE $†$ & $\mathrm{p}$ Value \\
\hline Death (all causes) & 1.35 & 1.99 & $<0.05$ \\
Vascular death & 1.42 & 1.79 & NS \\
Recurrent stroke & 1.08 & 0.30 & NS \\
Recurrent stroke/vascular death & 1.24 & 1.30 & NS \\
\hline
\end{tabular}

* Or hazard ratio comparing patients with atrial fibrillation with those with sinus rhythm. Ratio $=1$ implies no difference in risk, $>1$ implies a greater sinus rhythm. Ratio $=1$ implies no difference in risk, $>1$ implies a greater
risk with atrial fibrillation, and $<1$ implies a reduced risk with atrial risk with atrial fibrillation, and $<1$ implies a reduced risk with atrial fibrillation.

tTest of significance for the difference in hazard ratio for atrial fibrillation and sinus rhythm. If value $>1.96$ then $p<0 \cdot 05$.

$\mathrm{NS}=\mathrm{p}>0.05$

Allowing for these factors reduced the differences between the atrial fibrillation and sinus rhythm groups, and the only outcome showing a significant difference was death from all causes. Thus, although our data suggest that atrial fibrillation is an independent predictor of death in the early phase of stroke, it is not an independent predictor of early or late recurrence of stroke or of vascular death in the long term; it is a weak predictor of death from all causes in the long term

EFFECT OF VAIVAR HEART DISEASE ON OUTCOME

To see whether the presence or absence of valvar heart disease in patients with atrial fibrillation and sinus rhythm influenced outcome, we performed unadjusted log rank and Cox's regression analyses (adjusting for age and stroke type) on the short and long term risk of stroke, death from stroke or vascular death, vascular death, and death from all causes.

The number of patients with valvar heart disease was small, but the presence or absence of valvar heart disease did not significantly affect the outcomes studied.

\section{Discussion}

It is important to determine the role of atrial fibrillation in the pathogenesis and on the prognosis of a first stroke and on the long term risks of recurrent stroke and vascular death. If a major excess risk of vascular occlusive events (as seen in symptom free people with atrial fibrillation) persists in survivors of stroke such patients require special attention as a high risk group for secondary prevention. If, on the other hand, there is little difference in risk between having atrial fibrillation and sinus rhythm after a stroke then efforts at secondary prevention do not need to be focused on patients with atrial fibrillation.

PROGNOSIS OR LNTREATED NATURAI COURSE?

Many of the patients in this series were known to have had atrial fibrillation before the stroke occurred, though only a few had been taking anticoagulants and very few continued to receive anticoagulant or antiplatelet treatment after their stroke; if they did many did not receive long term maintenance treatment. Our results do not therefore represent a study of the natural course of stroke in a group of untreated patients, rather a study of prognosis in a group not treated aggressively. Any relative differences in prognosis in patients with and without atrial fibrillation are unlikely to be due to the use (or lack of use) of treatment in one group. Though limited use of antithrombotic and other treatments may have reduced the absolute risk of recurrent vascular events to some extent in both patients with atrial fibrillation and those with sinus rhythm, we think that any difference in absolute risk between the patients in our study and a completely untreated group would probably not be large. The Oxfordshire community stroke project therefore provides a representative sample of patients generally not treated with anticoagulants in whom the effect of atrial fibrillation on prognosis after a stroke can be examined.

METHODOLOGICAL STRENGTHS AND WEAKNESSES IN THIS AND PREVIOUS STUDIES

There have been several studies on atrial fibrillation and the risk of ischaemic stroke ${ }^{213-2131-51}$ but none fully meet all the methodological standards suggested by Haynes et al. ${ }^{21}$ Several studies used a potentially biased sample by including only patients admitted to hospital. ${ }^{15-211} 31-33$ 35-40 4+-52 Hospital based series are likely to contain an excess of more severe strokes. ${ }^{53}$

Our study satisfied (but not perfectly) the criteria for a methodologically sound prognostic study: 675 cases were followed without loss for up to six years, the sample was representative of all strokes in the community and not just those admitted to hospital, patients entered the study at any early stage of the natural course of the disease (with their first ever stroke) soon after its onset, the pathological type of the initial stroke was verified in over $90 \%$ of cases, the assessment of outcome events was prospective and as blind to the hypothesis under test as was practicable (since many hypotheses were being examined simultaneously). There were, however, some methodological weaknesses in our study. As this was a community based study we aimed to perform only the essential investigations on every patient. We did not have the resources to undertake detailed cerebral, cardiac, or arterial imaging and function studies as in some hospital based studies $3739+12^{42-47}$; we may therefore have underestimated the prevalence of certain cardiac disorders.

FREQUENCY OF ATRIAL FIBRILLATION IN PATIENTS WITH DIFFERENT TYPES OF CEREBROVASCULAR LESIONS

The frequency of atrial fibrillation in our sample of patients with first strokes is similar to that in previous community studies $3730+10+2$ and some of the large hospital based stroke registers ${ }^{45-49}$ but lower than in a hospital case series of hemiplegic strokes ${ }^{\circ}$ and a hospital registry of stroke in patients aged over $60 .^{5}$ Other studies have noted, as we have, that $2-6 \%$ of patients with primary intracerebral haemorrhage have atrial fibrillation..$^{55-48}$ It is not clear whether the atrial 
fibrillation was merely a transient arrhythmia due to the acute stress of the cerebral event because five out of the seven patients with primary intracerebral haemorrhage were known to have atrial fibrillation before the stroke. A maximum of only two of the seven cases could have been due to an arrhythmia as a result of the stress of the acute event; this is a small piece of evidence to support the notion that, in some strokes, the presence of atrial fibrillation is merely coincidental.

These data also highlight the importance of performing computed tomography early to exclude intracerebral haemorrhage in every patient with stroke and atrial fibrillation, before anticoagulants are given.

Of greater importance is the prevalence of atrial fibrillation in different subtypes of cerebral infarction. As anticipated, it is highest in patients with large infarcts presumed to be due to occlusion of the main stem of the middle cerebral artery (total anterior circulation infarction) and lowest in patients with lacunar infarction. In patients with lacunar infarction it is interesting to speculate whether the atrial fibrillation was the cause of the stroke or merely a marker of coincidental atherosclerotic cardiac disease. One other comparable community based stroke register has used a similar classification of cerebral infarction, and the prevalence of atrial fibrillation in the different subgroups was remarkably similar to our results. ${ }^{+1}$ Other groups have noted the association of atrial fibrillation with clinically large cortical infarcts ${ }^{15} 39+2+6+8$ and angiographically proved occlusion of the middle cerebral artery $^{12}$ and that a small proportion of patients with lacunar infarctions have atrial fibrillation..$^{39+1+2+6+851}$ In our series patients in atrial fibrillation often had other risk factors for cerebral infarction (table II). Thus, in a particular patient several potential causes for stroke may be present. Therefore, although some strokes in patients with atrial fibrillation are due to large cerebral infarcts presumed to be due to embolism from the heart, many must be caused by other mechanisms: primary intracerebral haemorrhage, atheroembolism from neck arteries, and occlusive small vessel disease of the intracranial perforating arteries. The exact proportion of non-cardioembolic strokes is unclear.

In the Oxfordshire community stroke project the prevalence of atrial fibrillation in patients with transient ischaemic attacks and those with ischaemic stroke was similar (14\% and $18 \%$ respectively). This contrasts with the results from a tertiary referral centre where the overall prevalence of atrial fibrillation was lower and atrial fibrillation much higher in patients with stroke than in patients with transient ischaemic attacks $\left(5 \cdot 6 \%\right.$ and $10 \cdot 6 \%$ respectively). ${ }^{30}$ The lower prevalence of atrial fibrillation in the study by Harrison and Marshall can presumably be accounted for by referral bias: elderly patients with an apparent cause (atrial fibrillation) might be less likely to be referred to a specialised centre than those without obvious cause. The reason for the difference in the prevalence of atrial fibrillation between patients with stroke and patients with transient ischaemic attacks within the tertiary centre is not clear.

\section{PRESENCE OF OTHER FACTORS}

Compared with patients with sinus rhythm, patients with atrial fibrillation were, on average, older and more likely to have diabetes mellitus, valvar heart disease, and mitral stenosis. On the other hand, cervical bruits (from the carotid or subclavian artery) were less common in patients with atrial fibrillation. The prevalence of hypertension and other markers of vascular disease (ischaemic heart disease and peripheral vascular disease) were similar in patients with atrial fibrillation and sinus rhythm. In our sample most cases of atrial fibrillation were not associated with rheumatic mitral stenosis and $74 \%$ were not associated with any form of valvar heart disease. As a recent review has suggested that the excess risk of stroke in thyrotoxic atrial fibrillation may be small,,$^{51}$ our inability to determine precisely the proportion of cases associated with thyrotoxicosis is probably unimportant.

EARLY PROGNOSIS: RISK OF DEATH WITHIN 30 DAYS

Atrial fibrillation was clearly associated with an increased risk of death within 30 days of stroke $(p=0.00003)$. Most of this excess was explained by the association of atrial fibrillation with large infarcts and by the older age of patients with atrial fibrillation, but a small excess risk persisted after adjustment for these factors. Others have found an increased early case fatality in atrial fibrillation ${ }^{1516+1951}$ and related it to the size of infarct ${ }^{15+1}$ and to packed cell volume. ${ }^{16}$ One plausible explanation for the increased early case fatality might be a high early risk of recurrent stroke in atrial fibrillation which has been reported by some groups ${ }^{1731333537}$ but has not been confirmed by others. ${ }^{215}{ }^{39-41}$ We observed a lower risk of early recurrence in patients with atrial fibrillation, so the excess risk of early death associated with atrial fibrillation cannot be accounted for by recurrences in our series. Another possibility for the excess mortality (not accounted for by infarct size and the patients' age) might be diabetes ${ }^{49}$; hyperglycaemia is an adverse prognostic factor in acute stroke. Detailed multiple regression analyses of all possible prognostic factors in acute stroke will be reported separately.

\section{EARLY PROGNOSIS: RISK OF EARLY RECURRENT STROKE}

In this series the risk of early recurrence was low in all patients with cerebral infarction and was lower than the risk found in some early studies ${ }^{1731353750}$ but comparable to that in some recent studies. ${ }^{21539-4146}$ This low risk is unlikely to be due to early treatment with antiplatelet or anticoagulant drugs.

The reason for the low early risk in recent studies might be because of differences in methods. Patients in our study were not monitored daily and we may have failed to detect some early recurrences. In addition, differing definitions of recurrent stroke in different studies could account for some of the differences. On the other hand, in our study at least it is unlikely that there was differential ascertainment of recurrences in patients with and without atrial fibrillation; thus our estimate of the relative difference of recurrence between patients with atrial fibrillation and those with sinus rhythm is likely to be unbiased even if we have underestimated the absolute risk of early recurrence. Detailed discussion is not warranted because the number of events was so small.

LONG TERM PROGNOSIS: RISK OF DEATH FROM ALL CAUSES, VASCULAR DEATH, AND RECURRENT STROKE

Several studies have found that after a stroke patients with atrial fibrillation have a substantially greater long term risk of recurrent stroke than have patients with sinus rhythm ${ }^{17} 193138$; others have not found a greater risk in atrial fibrillation. ${ }^{240}$ Many studies have reported life table risk of first stroke for stroke free patients with atrial fibrillation, but only two have reported life table risks for recurrent stroke after a first stroke during long term follow up ${ }^{20} 46$ and one hospital study has reported mortality only. ${ }^{51}$ Unadjusted life table analyses of survival in the Oxfordshire community stroke project clearly show a higher risk of death, of vascular death, and of the combined outcome recurrent stroke and vascular death with atrial fibrillation (table IV). However, much of the difference is due to the high early death rate from atrial fibrillation described above. The similarity in the risk of recurrent stroke in the Oxfordshire community stroke project in patients with atrial fibrillation and 
sinus rhythm is quite striking. The absolute risk of recurrent strokes in people who survived 30 days expressed as an average annual risk is similar to that reported by Marquardsen (for males in Marquardsen's study, the average annual risk was $14 \%$ in patients with atrial fibrillation and $8.5 \%$ in those with sinus rhythm). ${ }^{20}$ The stroke data bank study found two year recurrence risks for patients with first stroke of $12 \cdot 1 \%$ and $9.9 \%$ for those with sinus rhythm and atrial fibrillation respectively. ${ }^{46}$ Marquardsen's series may have had a worse prognosis than the other two studies because it consisted of a hospital based cohort of patients with more severe strokes in whom management of risk factors was probably not intensive..$^{20}$ The Framingham study reported a non-significant trend towards early recurrence in patients with stroke and atrial fibrillation, ${ }^{2}$ but average annual life table risks of recurrence were not reported (crude cumulative totals were not significantly different (atrial fibrillation $25 \%$, sinus rhythm $20 \%$ )).

Furthermore, in the Oxfordshire community stroke project, analysis of long term survival among patients who survived at least 30 days showed that although, in unadjusted analysis, death from all causes occurred significantly more often in patients with atrial fibrillation (table IV), multiple regression analyses, adjusting for the older average age and the larger cerebral infarcts among patients with atrial fibrillation, showed that none of these events occurred significantly more frequently with atrial fibrillation than with sinus rhythm. Of course, the lack of any relative difference between atrial fibrillation and sinus rhythm (with respect to long term outcome at least in this community study and in that of the stroke data bank $)^{46}$ emphasises that both atrial fibrillation and sinus rhythm have a relatively high absolute risk of recurrent stroke and vascular death ${ }^{46}$; attention to secondary prevention measures after stroke should not be overemphasised in patients with atrial fibrillation at the expense of those with sinus rhythm.

The Oxfordshire community stroke project was coordinated from the University Department of Clinical Neurology, Oxford. Three of the team (CW, PS, MD) then moved to Edinburgh, where the present analyses were undertaken. The project was undertaken with a grant from the United Kingdom Medical Research Council; PS and JS are supported by a programme grant from the council. JB and $M D$ are supported by grants from the Stroke Association. SB is a visiting fellow supported by a grant from the British Council. We thank the general practitioners and physicians in Oxfordshire who allowed us to study their patients. We also thank the research nurses Mrs S Price, Mrs E Mogridge, and Mrs C Clifford for performing the follow up examinations, and Miss L MacLean and Miss L Robertson for preparing the manuscripts and survival curves.

1 Wolf PA, Dawber TR, Thomas HE Jr, Kannel WB. Epidemiologic assessment of chronic atrial fibrillation and risk of stroke: the Framingham study. Neurology 1978;28:973-7.

2 Wolf PA, Kannel WB, McGee DL, Meedks SL, Bharucha NE, McNamara PM. Duration of atrial fibrillation and imminence of stroke: the Framingham study. Stroke 1983;14:664-7.

3 Brand FN, Abbott RD, Kannel WB, Wolf PA. Characteristics and prognosis of lone atrial fibrillation. 30-year follow-up in the Framingham study IAMA 1985;254:3449-53.

4 Flegel KM, Shipley MJ, Rose G. Risk of stroke in non-rheumatic atria fibrillation. Lancet 1987;i:526-9 (erratum Lancet 1987;i:878)

5 Wolf PA, Abbott RD, Kannel WB. Atrial fibrillation: a major contributor to stroke in the elderly. The Framingham study. Arch Intern Med 1987;147; $1561-4$

6 Cerebral Embolism Task Force. Cardiogenic brain embolism. The second report of the Cerebral Embolism Task Force. Arch Neurol 1989;46:727-43.

7 Flegel KM, Hanley J. Risk factors for stroke and other embolic events in patients with nonrheumatic atrial fibrillation. Stroke 1989;20:1000-4.

8 Davis P, Dambrosia J, Schoenberg B, Schoenberg D, Pritchard D, Lilienfield A, et al. Risk factors for ischemic stroke: a prospective study in Rochester, Minnesota. Ann Neurol 1987;22:319-27.

9 Boysen G, Nyboe J, Appleyard M, Srensen PS, Boas J, Somnier F, et al. Stroke incidence and risk factors for stroke in Copenhagen, Denmark. Strok 1988;19:1345-53

10 Cerebral Embolism Task Force. Cardiogenic brain embolism. Arch Neuro 1986;43:71-84

11 Kipecky SL, Gersh BJ, McGoon MD, Whisnant JP, Holmes DR Jr, Ilstrup
DM, et al. The natural history of lone atrial fibrillation. A population-based study over three decades. N Engl F Med 1987;317:669-74.

12 Petersen P, Boysen G, Godtfredsen J, Andersen ED, Andersen B. Placebocontrolled, randomised trial of warfarin and aspirin for prevention of thromboembolic complications in chronic atrial fibrillation. The Copenhagen AFASAK study. Lancet 1989;i:175-9.

13 Stroke Prevention in Atrial Fibrillation Group. Preliminary report of the Stroke Prevention in Atrial Fibrillation Group. Preliminary report of the
stroke prevention in atrial fibrillation study. N Engl f Med 1990;322:863-8.

14 The Boston Area Anticoagulant Trial for Atrial Fibrillation Investigators. The effect of low-dose warfarin on the risk of stroke in patients with nonrheumatic atrial fibrillation. N Engl F Med 1990;323:1505-11.

15 Britton M, Gustafsson C. Non-rheumatic atrial fibrillation as a risk factor for stroke. Stroke 1985;16:182-8

16 Lowe GD, Jaap AJ, Forbes CD. Relation of atrial fibrillation and high haematocrit to mortality in acute stroke. Lancet 1983;i:784-6.

7 Sage JI, Van Uitert RL. Risk of recurrent stroke in patients with atrial fibrillation and non-valvular heart disease. Stroke 1983;14:537-40

8 Sherman DG, Goldman L, Whiting RB, Jurgensen K, Kaste M, Easton JD. Thromboembolism in patients with atrial fibrillation. Arch Neurol 1984;41: $708-10$

19 Fisher C. Reducing risks of cerebral embolism. Geriatrics 1979;34:59-66.

20 Marquardsen J. The natural history of acute cerebrovascular disease. A retrospective study of 769 patients. Copenhagen: Munksgaard, 1969:138-59.

21 Haynes RB, Tugwell P, Sackett D. Epidemiology: a science for clinical medicine. Toronto: Little, Brown, 1985

22 Bamford J, Sandercock P, Dennis M, Burn J, Warlow C. A prospective study of acute cerebrovascular disease in the community: the Oxfordshire Community Stroke Project 1981-6. I. Methodology, demography and incident cases of first-ever stroke. I Neurol Neurosurg Psychiatry 1988;51: 1373-80.

23 Bamford J, Sandercock P, Dennis M, Burn J, Warlow C. A prospective study of acute cerebrovascular disease in the community: the Oxfordshire Community Stroke Project 1981-6. II. Incidence, case-fatality rates and overall outcome at one year of cerebral infarction, primary intracerebral haemorrhage and subarachnoid haemorrhage. $\mathcal{I}$ Neurol Neurosurg Psychiatry 1990;53:16-22.

24 Bamford J, Sandercock P, Dennis M, Burn J, Warlow C. The classification and natural history of different subtypes of cerebral infarction. Lancet 1991;337:1521-6.

25 Bamford J. Clinical examination in diagnosis and sub-classification of stroke. Lancet 1992;339:400-2.

26 Gardner MJ, Altman DG. Statistics with confidence-confidence intervals and statistical guidelines. London: British Medical Journal, 1989

27 Armitage P. Statistical methods in medical research. Oxford: Blackwell Scientific, 1971:135-8

28 Dennis M, Bamford J, Sandercock P, Warlow C. Incidence of transient ischemic attacks in Oxfordshire, England. Stroke 1989;20:333-9.

29 Peto R, Pike M, Armitage P, Breslow N, Cox DR, Howard SV. Design and analysis of randomised clinical trials requiring prolonged observation of each patient. I. Introduction and design. Br $\mathcal{F}$ Cancer 1976;34:585-612.

30 Dixon WJ. BMDP statistical software. Los Angeles: University of California Press, 1985:576-95.

31 Darling R, Austen W, Linton R. Arterial embolism. Surg Gynecol Obstet 1967;124:106-14

32 Koller R. Recurrent embolic cerebral infarction and anticoagulation. Neurology 1982;32:283-5.

33 Hart R, Coull B, Hart D. Early recurrent embolism associated with nonvalvular atrial fibrillation: a retrospective study. Stroke 1983;14:688-93.

34 Sacco R, Wolf P, Kannel W, McNamara P. Survival and recurrence following stroke. Stroke 1982;13:290-5.

35 Santamaria J. Hemorrhage and anticoagulation after nonseptic embolic brain infarction. Neurology 1983;33:1104

36 Harrison MJ, Marshall J. Atrial fibrillation, TIAs and completed strokes. Stroke 1984;15:441-2.

37 Kelley R, Berger J, Alter M, Kovacs A. Cerebral ischemia and atrial fibrillation: prospective study. Neurology 1984;34:1285-91.

38 Gustafsson C, Britton M. Prognosis after brain infarction in patients with nonvalvular atrial fibrillation compared with sinus rhythm. Acta Neurol Scand 1986;73:520.

39 Bogousslavsky J, Van Melle G, Regli F, Kappenberger L. Pathogenesis of anterior circulation stroke in patients with nonvalvular atrial fibrillation: the Lausanne Stroke Registry. Neurology 1990;40:1046-50.

40 Bogousslavsky J, Adnet-Bonte C, Regli F, Van Melle G, Kappenberger L. Lone atrial fibrillation and stroke. Acta Neurol Scand 1990;82:143-6.

41 Ricci S, Celani MG, Duca E, Scaroni R, Caputo N, Chiurulla C, et al. Ischaemic stroke and atrial fibrillation: a community based case-control Ischaemic stroke and atrial fibrillation: a community based case-contro Amsterdam: Elsevier, 1991:7-11

42 Olsen T Atrial fibrillation and stroke. f Neurol 1990;237:139.

43 Ricci S, Celani M, Guercini G, Rucireta P, Vitali R, La Rosa F, et al. First-year results of a community-based study of stroke incidence in Umbria, Italy Stroke 1989;20:853-7.

44 Britton M, de Faire U, Helmers C, Miah K, Ryding C, Wester PO Arrhythmias in patients with acute cerebrovascular disease. Acta Med Scand 1979;205:425-8.

45 Mohr JP, Caplan LR, Melski JW. The Harvard cooperative stroke registry: a prospective registry. Neurology 1978;28:754-62.

46 Hier DB, Foulkes MA, Swiontonowski M, Sacco RL, Garelick PB, Mohr JP, et al. Stroke recurrence within two years after ischemic infarction. Strok 1991;22:155-61.

47 Bogousslavsky J, Van Melle G, Regli F. Lausanne Stroke Registry: analysis of 1000 consecutive patients with first stroke. Stroke 1988;19:1083-92.

48 Van Merwijk G, Lodder J, Bamford J, Kester A. How often is non-valvular atrial fibrillation a cause of brain infarction? I Neurol 1990;237:205-7.

49 Candelise L, Pinardi G, Morabito A, Italian Acute Stroke Study Group. Mortality in acute stroke with atrial fibrillation. Stroke 1991;22:169-74.

50 Hart R, Easton JD, Sherman DG. Duration of nonvalvular atrial fibrillation and stroke. Stroke 1983;14:827.

51 Friedman PJ. Atrial fibrillation after stroke in the elderly. Stroke 1991;22: 209-14.

52 Petersen P. Thromboembolic complications in atrial fibrillation. Strok 1990;21:4-13.

53 Bamford J, Sandercock P, Warlow C, Gray M. Why are patients with acute stroke admitted to hospital? BMY 1986;292:1369-72.

(Accepted 2 October 1992) 